\title{
MARIN, C. (2019): RUPTURE(S). PARÍS: EDITIONS DE L'OBSERVATOIRE.
}

\author{
Eguzki Urteaga \\ Universidad del País Vasco, España
}

Claire Marin acaba de publicar su último libro, titulado Rupture(s) (Ruptura(s)), en la editorial de L'Observatoire. Conviene recordar que la autora es antigua alumna de la prestigiosa Escuela Normal Superior (ENS), doctora en filosofía y miembro del Centro Internacional de Estudios de la Filosofía Francesa Contemporánea en la ENS. Es actualmente profesora agregada en el Liceo Anfred Kastler de Cergy-Pontoise. Entre sus obras más relevantes, es preciso citar Violences de la maladie, violence de la vie (2008), La maladie, catastrophe intime (2014) y Rupture(s) (2019). Asimismo, ha coordinado una serie de libros colectivos, tales como De la nature à l'esprit, introduction à la philosophie française du XIXe siècle (2001), junto con Raynald Belay, L'épreuve de soi (2003) y Souffrance et douleur. Autour de Paul Ricœur (2013), redactado en colaboración con Nathalie ZaccaïReyners. Ha obtenido varios galardones, entre los cuales, figuran el Premio Literario de la Academia de Medicina 2008, el Premio Jean Bernard 2008 y el Premio Ética y Sociedad Pierre Simon 2010.

En la introducción de la presente obra, titulada "Nuestras vidas están hechas de rupturas", la filósofa indica que "la ruptura es un desgarro" (p.9). Ese desgarro se produce a lo largo de una vida común en la cual "las identidades de unos y de otros se han entremezclado tan estrechamente que nadie sabe dónde comienza y dónde se termina el otro" (p.9). La ruptura clara y limpia es imposible (p.9). Incluso rotos, "los lazos pueden seguir siendo sensibles, [como] fantasmas, testigos de una antigua vida. Permanece el rastro de todo lo que esta última ha inscrito en [las personas]", ya que se ha infiltrado e incrustado en sus carnes, en sus pensamientos, en sus "maneras de entender y de ser" (p.10). En ese sentido, es imposible pasar página. "El inconsciente se encarga de [recordar] estos rastros fantasmáticos e imposibilita [cualquier] diversión" (p.10).

Romper con su antigua vida, "es cambiar de manera de ver, pero también es cambiar de cuerpo, de forma. (...) La ruptura implica una profunda mutación, donde el cuerpo juega un rol central" (p.10). De hecho, "la ruptura es una experiencia física, corporal. [Se siente] ese dolor de la ruptura que es [sinónimo de] desgarro" (p.11). El momento más delicado acontece cuando se pierde a los seres queridos, a

\footnotetext{
${ }^{1}$ Profesor del Departamento de Sociología y Trabajo Social. Facultad de Relaciones Laborales y Trabajo Social. E-mail: eguzki.urteaga@ehu.eus
} 
la familia y a la vida en común que se ha inscrito en ellos, "que se ha encarnado" (p.11). La violencia del vacío y de la ausencia "impide dormir, comer, trabajar, vivir, puesto que la vida está interrumpida, rota" (p.11).

Incluso cuando la ruptura es "voluntaria [y] decidida, incluso cuando se inscribe en una afirmación de sí, una revelación de la identidad hasta entonces [acallada], una liberación del sujeto, sigue siendo dolorosa" (pp.11-12). Si todos los individuos están heridos por la vida y atraviesan momentos difíciles que los torturan, "todos no reaccionan de la misma forma", en función de su "fragilidad y solidez interior" (p.12). En cualquier caso, que la ruptura sea elegida o padecida, infringe "una torsión psíquica y física insoportable" (p.12). Deben soportar la deformación de su identidad y existencia (p.12). Pero, es cierto que, los que gozan de una columna vertebral, a la vez sólida y flexible, soportan mejor la ruptura (p.13).

Según Marin, las rupturas construyen quizás más los sujetos que los lazos (p.13). "La ruptura no es necesariamente visible [y] estrepitosa, se hace a veces sin cambios [bruscos, sino] a través de decisiones interiores, nuevas orientaciones, el abandono de ciertas [partes] de [la] existencia” (p.13). No en vano, en general, se produce "verdaderamente una ruptura cuando se opera una profunda transformación de los esquemas de acción y de pensamiento del sujeto" (p.14). La ruptura puede ser "una necesidad vital, una [cuestión de] supervivencia psíquica" (p.14). A veces, es necesario romper para salvarse, es decir escaparse, "rompiendo con lo que [lo] amenaza y [le] impide existir" (p.14). De la misma forma, es preciso crear, vía la ruptura, "las condiciones de aparición y de realización de sí mismo. Romper para revelar la persona que uno quiere ser" (p.14).

Cuando la ruptura es involuntaria, padecida, "vivida [como un] accidente, una catástrofe o una tragedia", provoca, lo más a menudo, "una modificación profunda de la manera de pensar y de vivir" (p.15). Se menciona, a menudo, el nuevo sujeto que surge de una ruptura. Se habla entonces de renacimiento o de volver a empezar (p.15). Para los optimistas, la ruptura permitiría ser verdaderamente sí mismo, aproximándose a su verdadero ser. Posibilitaría acceder a "una verdadera identidad, la de la [realización personal], aquella en la cual el sujeto se realiza en su singularidad, expresa [y despliega] su individualidad" (pp.15-16). Para los pesimistas, en cambio, "esta nueva vida, esta metamorfosis del sujeto, no [sería] otra cosa que un consuelo, una reconstrucción a posteriori, necesaria para soportar el drama, para dar sentido [a la absurdidad] de la muerte, de la enfermedad [o] del accidente" (p.16). No en vano, algo en las personas resiste a "la destrucción en la prueba de la ruptura, [ya que] el ser roto descubre [su capacidad de resistencia]" (p.16).

Para la autora, es preciso repensar la ruptura, "porque ha cambiado de forma, porque está más presente, porque podría ser la forma nueva o futura de [la] existencia en general" (p.17). Hemos entrado en "una época de rupturas o 
en un momento de rupturas" (p.17). A nivel ecológico, y, por lo tanto, político y socioeconómico, "debemos repensar, de manera urgente, nuestras maneras de vivir, de comunicarnos, de desplazarnos, etc." (p.17). A nivel social, es obvio reconocer que "las parejas [se separan o se divorcian], las familias se recomponen", etc. (p.18). La ruptura se ha convertido en algo corriente, en un contexto marcado por "el auge del individualismo y la aspiración de cada uno a la felicidad y al desarrollo personal" (p.18).

Pero, "si estas rupturas contemporáneas son visibles [e] identificables, las roturas de la existencia, no son por ello menores, [ya que] siempre han sacudido las vidas de [los seres humanos]" (p.19). A veces, una primera ruptura es necesaria para "ser capaz de ver y de soportar todas las demás" (p.19).

En el primer capítulo, dedicado a "la imposible fidelidad a sí mismo y a los demás", Marin observa que, si los actos revelan a las personas, crean igualmente personajes de los que quisieran deshacerse, dado que la libertad crea, a su pesar, unos "efectos de determinismo e incluso de alienación" (p.23). A veces, los sujetos se sienten "prisioneros de las expectativas de los demás", aunque resulten de una elección libremente realizada en el pasado (p.23). "Lo que se ha decidido, en plena conciencia, con convicción, coraje o placer, se convierte en [su cárcel]" (p.23). $\mathrm{Su}$ antiguo deseo se ha transformado en una trampa (pp.23-24). El sujeto debe continuar a actuar como siempre, "conformándose con sutiles variaciones, a pesar [de la repugnancia que le procura] la repetición, la desaparición del placer; a pesar de la necesidad de pasar [página]" (p.24).

En ciertos casos, nos dice la autora, "ya no es posible ser fiel. La fidelidad a sus amigos, a [su] amor, a su familia o a sí mismo se convierten en [imposibles]" (p.24). De hecho, "la constancia ha dejado de ser el efecto de un deseo interior, [sino que] se convierte en una construcción artificial, un esfuerzo en el cual el sujeto se agota para seguir siendo sí mismo, para mantener su rol, [a pesar de haber dejado de creer en él]" (p.24). Repite los gestos pasados sin habitarlos. "Ya se ha ido, [es] anterior a esta identidad, anterior a esta relación ya muerta (...). Se miente a sí mismo, finge ser lo que no es o lo que ha dejado de ser" (p.24). Es extranjero a esta vida, "donde tiene la impresión de morir [poco a poco]" (p.24).

Cuando "ser fiel a sí mismo exige tantos esfuerzos que vivir [se convierte en] una impostura (...), asumir sus roles habituales se hace imposible" (p.24). Entonces, "es preciso huir y traicionar sus compromisos" (p.24). A veces, "un ligero desfase, un sutil contacto, (...) hace estallar [el corsé] y [libera la persona] de una vida convertida en demasiado exigua" (p.25). Lo que hasta entonces "tenía sentido, [estaba] rodeado [y] protegido, acaba devorando y consumiendo [al sujeto que] sufre de esta identidad mal ajustada. Está al estrecho en su vida, (...) necesita [tomar] aire" (p.25). Ese deseo de despliegue "se expresa por la necesidad de 
cambiar de espacio geográfico, afectivo, profesional, psicológico. (...) Necesita algo nuevo, [un] movimiento, [una posibilidad, algo] vivo" (p.25). Sucede que un acontecimiento de una gran potencia psicológica, "nos haga incapaces de seguir siendo el mismo, por la profunda metamorfosis que [provoca] en nosotros, por el rol revelador que [tiene]" (p.25).

En estos casos, "cambiar se convierte en necesario, [es preciso] que ese desfase interior, esa modificación íntima [se crea], en aras de [la verdad], pero también porque debe ser vivida, retranscrita en unos actos, debe manifestarse al mundo" (pp.25-26). Debe convertirse en otra persona para salvarse a sí misma (p.26). Esta conversión es sumamente violenta, tanto para el propio sujeto como para su entorno, puesto que la persona cambia a veces hasta tal punto que se convierte en irreconocible (p.27). En ciertas circunstancias, "esta transformación del sujeto es [sinónimo de] liberación. A veces, es renuncia ante lo que nos sumerge. La grieta se acrecienta. Luchar deja de ser posible" (p.27). El sujeto carece de fuerza para seguir siendo el que era. Ya no puede ser, para un momento o para siempre, el que era. Convierte la fidelidad a sí mismo y a los demás en "una comedia y una impostura" (p.28).

El acontecimiento traumático es, a veces, antiguo y, de repente, "está reactivado por un cambio de configuración" (p.28). El individuo "se descubre impotente ante la fuerza de otros afectos, otras necesidades [y] otras dependencias" (p.28). De la misma forma, "la incapacidad de convertirse en aquel que se desearía [ser genera] un profundo sufrimiento" (p.29).

En el segundo capítulo, que se adentra en el análisis de la ruptura amorosa, Morin recuerda que, en ese tipo de rupturas, "permanece la sensación [de] una fractura íntima, que afecta profundamente a su identidad" (p.31). Que sea decidida o padecida, la ruptura interroga lo que son las personas o lo que creen ser, lo que las sacude y las cuestiona (p.31). De una ruptura, "se puede tener el sentimiento que es un error, un terrible desperdicio, o, al contrario, que es necesaria" (p.31). Permanecer imperturbable "sería negar la potencia de la modificación que se ha operado en [ellas]" (p.31). En esta configuración, la fidelidad a sí mismo deja de ser posible (p.31). "Un nuevo (...) amor (...), otra pasión (...) se han inmiscuido entre los amantes o han producido un desfase, [un distanciamiento]" (p.32). "Una experiencia nueva, feliz o trágica, ha intensamente sacudido el sentimiento de sí mismo, ha desviado las polaridades de la existencia, remodelando los afectos" (p.32).

A menudo, la ruptura amorosa revela las personas a sí mismas. Es "la expresión de una verdad interna, la afirmación de una nueva identidad compatible con la antigua y con los compromisos [adquiridos]" (p.32). A veces, los sujetos pueden tener la tentación de romper "para estar liberados de la fatiga de ser sí mismos, de la pesadez de una modalidad de existencia cuyo carácter definitivo es 
temido" (p.32). Es para "escapar a una identidad decepcionante y, sin embargo, profundamente [suya]" que huye del antiguo amor como si fuera "responsable de ese empobrecimiento de [su] Yo" (pp.32-33). Algunas personas rompen con "la esperanza de huir de ellos mismos. La ruptura [se asemeja entonces] a una liberación: dejan de ser ellos mismos. Romper es entonces menos la búsqueda de una vida interior, que una tentación del vacío, un goce [de la desaparición] o de la negación de [su ser]" (p.34).

En una ruptura, "el que rompe está tan roto como el que [abandona]" (p.35). Y, se espera del nuevo amor que llene ese vacío, pero "nada consolida esa fragilidad íntima. La pasión amorosa, lejos de colmar la fisura, amplía [la brecha]" (p.35). El sujeto abandonado está roto a nivel psicológico. Sinónimo de violencia amorosa y de herida narcisista, "la ruptura es una demolición en toda regla del ego" (p.35). Lo que convierte las palabras de ruptura en tan amargas, "es el hecho de que subrayan, con una agudeza molesta, estos fallos, estas debilidades que uno intenta esconderse a sí mismo" (p.36). Pone de manifiesto el desconcierto interno de la persona, su inquietud fundamental, "vinculado al profundo vacío que [intenta] disimular" (p.37). Algunas personas que han sido abandonadas varias veces, muestran cierta capacidad de resiliencia (p.37). Pueden consolarse viendo en la decisión de ser abandonado "un serio error de juicio" (p.38).

Pero, en ciertos casos, "la ruptura destroza. El derrumbe [interior] amenaza [de producirse]", y, a veces, acontece (pp.38-39). "En esa experiencia, el sujeto se deshace, se debilita" (p.40). Observa impotente el acontecimiento que lo destroza, se convierte "en testigo de lo que señala su [ejecución]" (p.40). En semejante situación dolorosa, como consecuencia de "ese efecto extremo del desamor sobre el ser [desamparado], el sujeto renuncia a sí mismo, se ausenta de él mismo" (p.41). En las situaciones más dramáticas, "el desamor destruye el ser abandonado. Se puede morir psíquicamente de una pena de amor, vaciarse de sí mismo, desaparecer" (pp.41-42). En esta "brusca revolución interna", la persona ya no sabe quién es (p.42). Si todas las rupturas amorosas no son tan violentas, "el desamor [produce] una profunda sacudida" (p.42). La separación es cruel porque, del día a la mañana, la persona descuidada deja de ser "atractiva, inteligente, generosa o graciosa. (...) Es la certidumbre de [su] identidad que vacila. La ilusión de sí mismo desvanece" (p.42).

La ruptura provoca igualmente la vergüenza de convertirse en objeto de vergüenza. "No es solamente perder su valor, es ser considerado como indigno de amor" (p.43). La cuestión de su valor está en juego en la relación amorosa (p.43). Por lo cual, "el desamor [se convierte] en la experiencia cruel de una desvalorización" (p.44). Ser abandonado, nos dice la autora, "es sentirse amputado de una parte vital de sí mismo. (...) El cuerpo del amor, ese cuerpo quimérico que el amor había 
formado, se escinde, se desgarra" (p.44). Lo que se echa en falta en la ruptura, "es el tuteo de las carnes, las palabras murmuradas, [el movimiento ágil] de las manos, el ballet de los cuerpos [entrelazados] y [separados] a la vez, que se abandonan el uno al otro en el sueño, al tiempo que se protegen mutuamente" (p.45). Lo que se echa de menos, "es el cuerpo del otro como prolongación del [suyo], o, más exactamente, como parte del [suyo]'” (p.45).

La ruptura provoca un desgarrón, porque "cada uno intenta reencontrar su propio cuerpo allá donde el amor y la vida emparejada había creado, a lo largo de los años, (...) un cuerpo común [que] estaba entrelazado" (p.46). La ruptura es "la experiencia del desgarro. Desgarro de lo que [se consideraba] como suyo, de lo que [se había incorporado a su ser]" (p.46). Con la separación, el otro retira "esta piel de amor, este envolvimiento protector y reconfortante, su presencia y su atención" (p.46). Priva el sujeto de "sus miradas seductoras, orgullosas o [bondadosas]" (p.46). Además de ser fragilizado, está privado de sí mismo, privado de su ser y de su cuerpo, "como amputado" (p.47).

El final de una historia de amor se manifiesta "en la modificación de un ritmo implícito, ritmo de los cuerpos, que se desfasa" (p.47). Los amantes dejan de andar del mismo paso (p.47). Pequeñas señales precursores aparecen, "la coreografía íntima pierde de su pujanza, de su evidencia. Rompiendo esta costumbre común, el cuerpo [indica] que [se] ha [creado] una distancia. Estos ligeros distanciamientos, estas pequeñas rupturas en la continuidad de los gestos familiares traicionan [el alejamiento del ser], un afecto que se debilita" (p.47). El silencio posterior a la ruptura es "de una gran violencia. El discurso, [el murmullo], la ironía: todo lo que la voz [expresa] de atención, de afecto, de deseo desaparece" (p.48).

Algunos no rompen, prefiriendo vivir como fantasmas, desapareciendo sin decir nada, conformándose con desaparecer (p.48). Pero, no es suficiente desaparecer para "dejar de existir en la [mente] y el cuerpo del otro. Porque el amor deja en [sí] los rasgos del cuerpo amado, porque ha moldeado el [suyo], permanece durante un largo periodo inscrito. (...) Tortura de la memoria amorosa que [cualquier cosa reaviva] cuando [precisamente] se quería olvidar. Fuerza de los objetos y de los espacios que rememoran el antiguo amor" (p.48). En ese sentido, no es siempre posible superar la ruptura. "Se muere todavía de amor. Se puede enredar en la ruptura, padecida de un modo trágico, hundiéndose en su drama, vivida como una experiencia de la maldición” (p.49).

La ruptura "nos agrede físicamente. Es una experiencia sensible, encarnada. La obsesión de la pérdida nos roe interiormente. (...) Esta violencia simbólica produce un efecto físico. Corazón enloquecido, palpitaciones, temblores, vértigo, nausea" (p.47). En efecto, la ruptura se inscribe en los cuerpos. "Espalda abovedada, rasgos estirados, voz temblorosa, silueta adelgazada" (p.49). El dolor de la ausencia 
provoca "una sensación de malestar, (...) de quemadura. Presión en el pecho, aliento corto, sudación, el cuerpo manifiesta la brutalidad de la desaparición" (p.50). El cuerpo se consume ante esa ausencia (p.50). De hecho, "el cuerpo está todavía habitado por el recuerdo de la presencia del otro, que solo es [sinónimo de] tortura. Esta presencia, que era un principio vital, [se convierte en] una violencia interior, en un elemento destructor" (p.51). El cuerpo abandonado es irreconocible. Ya no está investido "por las miradas, las caricias, las huellas del otro, y solo vive al ralentí sobre un modo de supervivencia, en un abandono redoblado, (...) maltratado" (p.51).

La ruptura es, asimismo, desfiguración, dado que la vida y el ser cambian de forma y el sujeto está deshecho. Algo en el sujeto envejece prematuramente y la cara conserva los rasgos de esta demolición (p.52). Reduce su capacidad "de resistencia y de reacción" (p.54). Además, la ruptura saquea y devasta el mundo, dejando un mundo, a la vez, superpoblado y devastado (p.54). "Las cosas, reliquias de la antigua vida compartida, permanecen, al tiempo que cambian de estatus" (p.55). "Todo lo que era familiar parece extraño y sospechoso, cómplice de una traición" (p.55). Por lo cual, la ruptura amorosa obliga a una "desolidarización dolorosa", dado que las cosas están impregnadas de sentimientos experimentados en el momento de su adquisición" (p.56) y de un mundo común que ha dejado de existir (pp.56-57). A menudo, "la separación se estira, se pierde en puntos de suspensión, en silencios, en dudas. Pasa por circunvoluciones [e] incertidumbres" (pp.57-58). "El dolor se esconde en los detalles de la memoria. (...) Las secuelas de la ruptura son como unas partículas que [permanecen] dolorosamente en los márgenes de nuestros pensamientos" (p.58).

Afortunadamente, poco a poco, "viene el tiempo en el cual el dolor se [atenúa], la ausencia se convierte, de cierta forma, en familiar" (p.60). Se produce "un trabajo de separación, de desunión, de reconfiguración de los espacios físicos y psíquicos, un esfuerzo de adaptación a la ausencia del otro" (p.60).

Algunas veces, sin embargo, "el amor cesa brutalmente. [Se impone] la idea de un punto de ruptura, de un momento de vuelco [imparable] que rompe inmediatamente la relación" (p.60). Si, en algunos casos, "la conciencia del fin del amor es (...) inmediata, puede ser que ese irreparable aparezca retrospectivamente, cuando uno se miente a sí mismo para preservar, a cualquier precio, la relación a la cual no quiere renunciar" (p.61). "Se puede hacer todo lo posible para prolongar artificialmente una historia [de amor] de la que se sabe que, en realidad, ya está rota, o se puede decidir cortar de raíz, poner fin brutalmente a lo que agota, en la repetición de falsas rupturas" (p.62). De cuando en cuando, se producen rupturas en cascada, ya que una ruptura sentimental puede desembocar en una ruptura profesional, que provoca, a su vez, un cambio de vida (p.63). De hecho, "la deflagración de la ruptura se propaga a numerosos 
ámbitos. Romper con una persona se convierte, entonces, en el punto de partida de un nuevo comienzo" (p.63).

En el tercer capítulo, que estudia la conversión a sí mismo, Marin constata que, la persona tiene a veces la sensación de no ser lo que es, "de jugar un rol, de estar al margen de su propia vida, sin adherirse a ella" (p.65). Siente "un malestar y una vergüenza a la idea de fundirse en esa vida" (p.65). Experimenta "una ausencia, una insatisfacción, una tensión interior se intensifica de manera tan aparente que se hace necesario romper con lo que [era]" (p.65). Se quiere ser otra persona, sin saber precisamente quién. Acceder a una nueva identidad implica una ruptura con el entorno y una ruptura interna dolorosa que conduce a una verdadera crisis (p.66). "La ruptura con lo que [esta persona] era es una transformación que pasa por la (...) muerte de lo que sobrevive en [ella]. Debe deshacerse de las formas inscritas en [ella], romper con lo que era hasta entonces" (p.66). Pero, esta ruptura es igualmente un fracaso, "incluso cuando obedece a una necesidad imperiosa. (...) La ruptura es también vivida como una traición y un acto de cobardía, [dado que] se abandona su antigua vida" (p.67).

A menudo, ese camino hacia su verdadero Yo empieza con antelación, "de manera subterránea. La ruptura está consumida, la falla se ha agrandado" (p.68). Antes de que uno se lo confiese a sí mismo, que lo reconozca, algo en su seno sabe, de manera casi orgánica, que su vida lo ahoga y lo empuja hacia lugares donde "se respira, liberado, desplegado" (p.69). Experimenta una muerte interior, un distanciamiento respecto a ese ser restringido. Se encuentra al estrecho en su uniforme (p.69). En ese contexto, debe aprender a estar solo, "a definirse por sí mismo" (p.69). Debe "despojarse de todo atributo exterior y soportar la angustia [que le procura] una identidad vacía" (p.69).

Para Charles Juliet, "la ruptura es necesaria, es radical y se plantea como la condición del advenimiento de un Yo verdadero. Es vital deshacerse de un falso Yo, completamente moldeado desde el exterior e impuesto con mucha rigidez" desde la niñez (p.71). A menudo, las crisis traducen una presión social y familiar excesiva que pesa sobre el niño que se siente profundamente amenazado (p.71). Ese sufrimiento implica que "ciertos adultos elijan [alejarse] de trayectorias profesionales brillantes para afirmar algo más esencial, [ya que] el éxito se hace a veces pagando el precio de una traición íntima, que acaba dando la impresión de jugar una comedia insoportable" (p.72). De hecho, es posible tener todos los atributos del éxito profesional y tener la sensación de "haber pasado al lado de su vida" (p.73).

La ruptura interna toma diversas formas y todas las rupturas no son necesariamente tan radicales (p.73). Pero, correr el riesgo de reencontrarse, es también correr el riesgo de perderse, y ese camino es a menudo costoso (p.73). 
"Descubrir el que uno es o el que desea ser no es necesariamente una violencia, sino que es, a veces, el fruto de una larga interrogación sobre sí mismo" (p.73). La necesidad de ruptura se impone inicialmente de manera negativa, "es en la frustración o el vacío que se encuentra la fuerza de arrancarse a una existencia echa de artificios. Es también la vergüenza de sí mismo que conduce a convertirse en otro" (pp.73-74). E, incluso cuando la ruptura tiene tintes positivos, sinónimos de afirmación y de revelación de sí mismo, "en una lógica de ascenso y una perspectiva de autenticidad, tiene igualmente tintes de culpabilidad, acompañado de una impresión de traición" (p.74).

De hecho, la ruptura no es sencilla y es, a menudo, costosa (p.74). "La afirmación de una muerte del antiguo mundo, la pretensión de romper las leyes, de hacer el duelo del antiguo Yo, [infravalora] la potencia de los fantasmas, la memoria del cuerpo, la fuerza de las costumbres afectivas [y] de las ataduras infantiles" (p.75). En realidad, la ruptura es "un arrancamiento [constantemente] reiniciado, [hecho] de idas y vueltas interiores [y de] inquietudes. Es un largo trabajo de desvinculación, de distanciamiento y de apaciguamiento afectivo. Es preciso amaestrar la violencia de los sentimientos que suscita en [su seno]. Es necesario tolerarlas como el efecto inevitable del trastorno que produce la ruptura y domarlas a medida que [avanza el tiempo]" (p.75).

En el cuarto capítulo, que alude al "placer de la dispersión", la filósofa francesa constata que la sucesión de pequeñas rupturas y las yuxtaposiciones de identidades sin vínculos entre sí se combinan en función de las circunstancias (p.77). Estas rupturas íntimas, "que hacen emerger un nuevo sujeto, no son solamente dolorosas, sino que son, a la vez, profundamente inquietantes y excitantes. Interrogan la representación fundadora del sujeto, en su constancia, (...) continuidad [y] duración. Plantean la cuestión de la unidad [del] ser" (pp.77-78). Aunque exista un imperativo social de unidad, las personas están constantemente dispersadas y soportan precisamente su existencia porque son capaces de estar mentalmente en otro lugar, porque pueden jugar con lo real cubriéndolo de un velo imaginario [y] porque superponen a la realidad "unas proyecciones [y] unas imágenes fantasmadas" (p.79). Para la autora, "necesitamos ser varios individuos diferentes", deshaciéndonos de unos y reencontrándonos con otros (p.79). "No es solamente que juguemos diferentes roles, sino que nuestro ser no es uno [y] que se manifiesta bajo diferentes formas" (p.79).

Para Pontalis, las diferentes formas de la vida de los sujetos y los roles que juegan dan a sus existencias "una forma casi incoherente; se aparenta a una sucesión de escenas oníricas, sin vínculo, sin lógica aparente, y crea una sensación desagradable de dispersión" (pp.82-83). Esa variedad hace "el interés y el dolor de [las] vidas. Al contrario, una existencia que se reduciría a un solo rol, a una 
sola partitura, acabaría convirtiéndose en pura repetición” (p.83). Por lo cual, esta dispersión es necesaria "para escapar a la tensión que suscita el esfuerzo de ser sí mismo" (p.84). Bergson fue el primero en subrayar "la fatiga de ser una persona, la tensión que esta continuidad interior unificadora [impone] a la conciencia" (p.84). Es una suerte y un recurso de los que disponen los sujetos cuando su "existencia se rompe en una prueba, un fracaso o una pérdida irreparable" (p.87). Estas diferentes facetas de la personalidad no están en competencia, sino que "conviven, [ya que] una toma el relevo de la otra, se apoyan y se imbrican, se nutren mutuamente" (p.87). Esta composición interior "de las identidades, de las edades, de las sensibilidades [y] de las creencias nos libera del peso de ser solo nosotros mismos, permitiendo una dispersión alegre y estimulante" (p.88).

No en vano, existe un riesgo de agotamiento "cuando estas diferentes identidades endosadas son vividas como otros tantos [imperativos] sociales, culturales, familiares [y] profesionales. La fatiga de ser sí mismo nace de la desmultiplicación de los roles a desempeñar en [la búsqueda] del rendimiento" (p.88). A partir del momento en que "cada una de estas maneras de ser se convierte en una carga y parece estar impuesta, es difícil ver en ella una dispersión estimulante del sujeto [y] un reparto feliz de los equilibrios de vida" (p.88). Tampoco se trata de negar "la realidad trágica de las patologías de la disociación" (p.88), puesto que no es siempre posible deshacerse serenamente de sí mismo, "sin derrumbarse, sin caer en el caos donde todo está confundido" (p.89). En estos casos, estamos ante "una verdadera deserción del sujeto o de su fragmentación interior. (...) Cuando el sujeto no [consigue mantener] el esfuerzo de una unificación, ya no soporta la tensión que semejante síntesis de sí mismo exige, ve su personalidad fisurarse y, algunas veces, desmultiplicarse en un caos interior trágico y doloroso" (p.89). La enfermedad psíquica se convierte entonces en una manera de huir de sí mismo "cuando la identidad [personal] parece insostenible y cuando otro tipo de huida es imposible" (p.90).

En el quinto capítulo, centrado en el "ser accidentado", Morin observa que el enfermo o el discapacitado, "es el que ha perdido su solidez, su fuerza, en el sentido físico pero también psíquico. [El accidente] convierte el sujeto entero en vulnerable [y] frágil. Se convierte en [un] cojo que carece de seguridad en sí mismo" (p.94). Para la persona que se rompe un brazo o una pierna, el mundo cambia. "No tiene ninguna facilidad, habilidad corporal, evidencia de los gestos y de los desplazamientos. (...) Todo su cuerpo parece inutilizable. Esta experiencia es a priori una experiencia de la pérdida y de la extrañeza" (p.94). El sujeto pierde el cuerpo que lo apoya y que es cómplice. Pierde la costumbre de su cuerpo que convierte en "una brújula enloquecida" (p.94). Esto permite revelar otro ser y otra manera de ser. "Una presencia que ha ignorado durante años, que ha dejado siempre en la sombra. Así, los accidentes revelan los fantasmas, las virtualidades de [su] Yo" (p.95). 
El accidente se convierte entonces en "una oportunidad de invertir esta parte de [sí mismo] y de [explorarla]" (p.95). Esta otra parte de sí mismo puede interpretarse como "una figura de la vulnerabilidad, un ser diferente, disminuido, menos ágil, pero es también, por la atención que exige, un ser que actúa de otra manera, que observa el mundo y que se [relaciona con él] de otra forma, que tiene otra mirada" (p.95). El accidente se convierte en "una suerte de experimentación de sí mismo" (p.96). El sujeto que sufre es "un ser desplazado, exiliado, amputado. El sufrimiento altera [su] costumbre de ser, [le] hace perder [su] naturalidad, rompe esta complicidad silenciosa entre el cuerpo y el espíritu" (p.96). El cuerpo falla, el espíritu se ausenta, "desposeído por esta desaparición de una parte de sí, [obnubilado] por el sufrimiento que genera la enfermedad o la herida" (p.96). Pero, esta faceta nos aprende algo sobre nosotros mismos. "Ser desplazado, es descubrirse de otra manera y esta fragilidad no es solamente un desfallecimiento, [sino que] nos indica otra manera de ser, otro estilo de existencia" (p.96).

En el sexto capítulo, consagrado a los nacimientos y a las separaciones, Morin incide en el hecho de que el nacimiento constituye la primera ruptura, "por las profundas transformaciones que presupone y engendra" (p.99). Transformaciones del cuerpo de la mujer, que padece importantes cambios, pero también de la mente, en su relación a sí misma (p.99). La madre renuncia, al menos momentáneamente, a permanecer sola y separada de los demás. "Rodea, acompaña y acepta pasar a un segundo plano detrás del niño que trastoca las prioridades, el orden del [día] y las libertades" (pp.99-100). Además de ser un inicio, el nacimiento es, "para la madre, para el niño y para la pareja, una ruptura profunda y molesta. Puede modificar y redefinir otras relaciones familiares y afectivas" (p.100). De hecho, "el nacimiento desplaza, redefine los contornos y los límites de las identidades [y] de las relaciones" (p.100). La futura madre "debe [crear un espacio], crear en ella, en su cuerpo, un espacio que acoja, alimente y proteja a su [progenitura]. Simbólicamente, [se retrae] para hacer pasar el bienestar de su hijo antes de su propio confort y [de] sus deseos" (p.100).

Desde su embarazo, "la mujer está [cargada] de responsabilidades vitales. Debe llevar el niño y darlo a luz en las mejores condiciones posibles. Su dolor, su incomodidad, sus inquietudes, su sufrimiento, su tristeza pasan a un segundo plano. El parto concreta ese movimiento de relegación, que va hasta el riesgo vital para la madre" (p.101). Además, "el nacimiento es el encuentro entre dos extranjeros que han vivido durante meses en la mayor proximidad posible, proximidad corporal pero también (...) psíquica" (p.101). En ese sentido, el nacimiento puede ser vivido y pensado como "un arrancamiento de una gran violencia" (p.101). La ocupación de la madre por el niño "parece no desaparecer jamás verdaderamente" (p.102).

No en vano, es preciso ayudar el niño a "nacer una segunda vez, es decir a nacer al mundo y a sí mismo" (p.102). En efecto, ser madre es, a la vez, preparar 
“el niño a estar en el mundo y posibilitar la separación, sea cual sea el dolor que ésta engendra. Es hacer frente a una doble ruptura: la del nacimiento y la [de la separación] venidera, cuando el niño abandonará el nido familiar" (p.103). Pensando el nacimiento como "una separación violenta, un arrancamiento", es posible pensar "otras rupturas de la existencia. Toda ruptura [reactiva], de cierta manera, ese arrancamiento [inicial]" (p.103). Esto significa que "cualquier nacimiento o renacimiento, por la ruptura que presupone, debe ser acompañada. Pensar la ruptura, es pensar también la hospitalidad que acogerá la individualidad en tránsito (...) y le ofrecerá una esfera de seguridad donde desplegar su ser vulnerable, donde afirmar su identidad todavía frágil” (pp.103-104).

Al mismo tiempo, "toda ruptura, para ser soportable, debe llevar a un acto de creación. Debe permitir a la subjetividad aparecer o afirmarse, crearse sin trabas, sin dominio" (p.104). Según la autora, "el nacimiento es, para la criatura, un sufrimiento psíquico, sufrimiento de la situación, de la primera separación, [sinónimo de] agresividad del mundo exterior, frio, ruidoso, cegador" (p.104). Desnudo, "el niño está expuesto, devuelto a su gran vulnerabilidad, después de haber sido llevado e íntimamente unido, rodeado por la burbuja matricial. (...) El cuidado [se convierte] entonces [en] el reconocimiento y la atención de esta fragilidad del niño" (p.105). Por lo cual, "es preciso prolongar por la dulzura del toque, el calor de la piel, las palabras reconfortantes susurradas, la sensación de estar constantemente rodeado de presencia, de atención [y] de cuerpos benevolentes" (p.105).

No en vano, la fragilidad del otro nos fragiliza, y nos obliga, de manera a veces brutal, a confrontarnos a nuestras propias vacilaciones (p.106). En ese caso, "el nacimiento es menos (...) un acontecimiento que un proceso, una separación progresiva, acompañada del cuidado que [transforma] la vulnerabilidad en fuerza" (p.107). Esto implica que "la constitución de una subjetividad pasa por un acto creador, la creación de un espacio interior propio" (p.107). Es preciso procurar al recién nacido una "nueva piel de afecto y de confianza" (p.108). Es porque esa protección inicial ha sido deficiente que algunas personas "siguen siendo más sensibles a la agresividad del mundo" (p.108). En definitiva, "si, a veces, la ruptura es la condición necesaria de un renacimiento, (...) no puede hacerse sin un nuevo envoltorio protector que recubra de una piel de palabras, de gestos y de atención, la herida del trauma" (p.109).

En el séptimo capítulo, que se centra en la ruptura con la familia, Morin indica que, en esta materia, a veces, no es en el maltrato cotidiano sino en su ausencia que el sufrimiento estalla con un efecto retardo. Es "en el desfase, en la distancia y en la comparación con otras vidas que aparece, como en una deflagración, la realidad de la dureza padecida" (p.111). "Cuando la vida se hace más dulce, el pasado oscuro parece intolerable y estalla a la cara" (p.112). Descubriendo cómo 
viven los demás, uno se horroriza ante su vida y se avergüenza de ella. "Vergüenza de su grosería, de su fealdad, de su violencia, de su estupidez" (p.112). Ciertos padres son incapaces de amar sin destruir. Cuando la violencia impregna los gestos del adulto, la única solución consiste en huir (p.112). "Se trata de salvar su vida, de huir para [renacer] de nuevo en otro lugar, deshacerse de las mitologías familiares y extraerse del salvajismo de ciertos lazos, para escapar a la devoración" (p.112).

La única solución consiste en la ruptura radical. "El desprendimiento que permite sobrevivir; que se trate de liberarse de una lealtad tóxica, de lazos venenosos, o, más simplemente, de reconocer la realidad de una diferencia demasiado grande para permitir un acuerdo o una real comprensión" (p.114). Algunas veces, el vínculo familiar nos convierte en rehenes, privándonos de una vida psíquica propia. Entonces, es necesario separarse "para nacer a sí mismo y provocar el irreparable desprendimiento" (p.115). Es preciso correr el riesgo de la ruptura, "una ruptura verdadera de la que nace la sensación de vivir, la sensación de existir en primera persona, y no a través de la madre" (p.116). Pero, "esto supone afrontar la culpabilidad de una [ejecución] de la madre" (p.115). "Sacrificar la madre, romper el vínculo para acordarse a sí mismo una zona de existencia, construir o reconstruir un espacio íntimo: cuando el vínculo agota más que alienta, es necesario renunciar a él" (p.116).

En ciertos casos, "la catástrofe (...) ayuda [los sujetos] a salir de sus vidas alienadas" (p.117). Sucede también que "esta ruptura se produzca por sí misma, provocada por un acontecimiento paroxístico cuya violencia psíquica provoca una suerte de reflejo de supervivencia" (p.117). Si ciertas rupturas son silenciosas e interiores, "no son por ello menos radicales y definitivas. Se puede calificar ese punto de ruptura en el momento en el cual algo se rompe interiormente en nosotros. Algo se derrumba. Una energía que mantenía la relación se [debilita]. Silenciosamente, pero con tal sentimiento de evidencia, que la duda ya no es posible" (p.117). El punto de ruptura es ese momento en el cual "se renuncia a un vínculo, se deshace o se corta. Es el momento en el cual se deja de creer en alguien, de esperar algo de él. [La] capacidad de confiar en él se ha agotado a medida de las decepciones, de las mentiras, de las violencias o de las traiciones" (p.118). A veces, la palabra no crea la ruptura, sino que es su ausencia. Alude a la "crueldad de lo que no se dice, de lo que no se hace. Las palabras y los gestos que no vienen, estos insoportables [silencios] suspenden la relación. Las frases que no se pronuncian destruyen a veces más que [las injurias]" (p.119).

En el octavo capítulo, dedicado a las "desapariciones", la filósofa gala indica que "existe una manera muy particular de perder a una persona a la que tenemos afecto, cuando la enfermedad la arranca a nosotros, al tiempo que la mantiene presente, viva pero irreconocible, incapaz de mantener su rol" (p.124). 
Nos corresponde, entonces, "reavivar ese vínculo que se apaga a medida que el otro [desvanece] y se ausenta de esta relación" (p.124). Esto acontece "cuando la patología imposibilita la manifestación de los sentimientos, priva de diálogo, acalla incluso la queja y la reduce a unas lágrimas, a unos sollozos ahogados" (p.124). Corresponde al allegado asumir "la carga agotadora de retejer, en cada instante, un lazo que se deshilacha, de [mantener] una relación que, a veces, es el único en querer [conservar], mientras que el enfermo se hunde en la inconsciencia total" (pp.124-125). De hecho, "para el allegado que visita regularmente al paciente, la constatación es la de una hemorragia de la presencia. Cada nuevo encuentro (...) solo puede constatar la pérdida diluida del amor, el desmoronamiento perlado de la relación, reducida a unos fragmentos de frases" (p.125).

Se produce, asimismo, una hemorragia del reconocimiento: "hemos dejado de reconocer el otro que tampoco nos reconoce. Solo queda el recuerdo de la persona a la cual agarrarse con [dificultad] para continuar a ver en ella el ser querido" (p.126). Ante esta situación, es necesario "contemplar una ruptura mental, una disociación". Es preciso "separarse, distinguir las personas que son, sin embargo, las mismas. Guardar el recuerdo feliz de la persona querida y continuar a amarla y, al mismo tiempo, conseguir separarla de la que [está ante] nosotros en la negación misma de ese amor" (pp.129-130). Es imperativo romper, "porque la enfermedad destruye la relación y amenaza, a veces, de contaminar los recuerdos felices [con] imágenes sórdidas, echa la sospecha retrospectiva sobre la naturaleza misma de la relación pasada" (p.130). La enfermedad que despoja el sujeto de su identidad, "acaba destruyendo (...) la posibilidad misma de la relación y del mantenimiento de la presencia al lado del ser anteriormente querido" (p.130).

En el último capítulo, titulado "Atravesar la noche", Marin recuerda que "la noche es el lugar de las angustias y de la memoria torturadora. Estamos, a veces, presos de ella, impotentes frente a las obsesiones vivas, incapaces de atravesarla en la inconciencia. Nuestros insomnios están hechos de recuerdos demasiado presentes" (p.141). Es preciso "instaurar unos límites al dominio del pasado sobre el presente, impedirle que invada el instante vivido para no encerrarnos en la mera repetición, la rumia y el insomnio. (...) El insomnio es la imposibilidad de dejarse llevar, el rechazo del sueño como abandono" (p.141). El insomnio "distiende el presente, rechaza la [interrupción] del pasado, se agota en ese esfuerzo vano sin darse cuenta de ello" (p.142). No obstante, "no tenemos todos la misma disposición a olvidar el pasado, lo que significa, en realidad, transformarla. No somos todos capaces de apropiarnos parcelas del pasado, de digerirlo, de retirarse de él" (p.142). "Es porque es un arrancamiento que el olvido es, a veces, tan difícil, porque confirma la pérdida definitiva de un ser o de una manera de ser de la que no [creemos] poder soportar la ausencia sin [deshacernos]" (p.143). 
Al término de la lectura de Rupture(s), es preciso reconocer, además de la originalidad del objeto de estudio y la manera de abordarlo, la sutileza con la cual la autora trata los diferentes tipos de ruptura, desde las rupturas amorosas y familiares, hasta las rupturas que representan el nacimiento, el fallecimiento o la enfermedad. La pertinencia del propósito es tal que parece que Claire Marin las ha experimentado todas y ha sido capaz de extraer conclusiones filosóficas sumamente profundas y ajustadas a la realidad íntima y social. Alude a múltiples referencias literarias que le permiten ilustrar sus tesis con elegancia gracias a un estilo claro y preciso, de carácter, a la vez, literario y poético. No en vano, la filósofa gala oscila constantemente entre el "yo", el "nosotros" y el "ellos", de modo que el lector no sepa, hasta qué punto, la autora ha efectivamente vivido, en su propia carne, lo que expone con suma agudeza. Asimismo, Marin peca por un excesivo pesimismo, especialmente cuando evoca el nacimiento que asemeja a un arrancamiento traumático. Por último, además del desequilibrio existente entre los distintos capítulos que abordan otras tantas rupturas, se echa en falta un apartado de conclusiones que recoja las principales ideas defendidas a lo largo del libro.

En cualquier caso, y más allá de estas reservas, la lectura de esta obra, tan breve como maestra, es sumamente recomendable para mejorar nuestro conocimiento y nuestra reflexión sobre las diferentes formas de ruptura.

\section{BIBLIOGRAFÍA}

Belay, R. y Marin, C. (dir.) (2001): De la nature à l'esprit, introduction à la philosophie française du XIX siècle. Lyon: Presses de l'École Normale Supérieure.

Marin, C. (dir.) (2003): L’épreuve de soi. París: Armand Colin.

Marin, C. (2008): Violences de la maladie, violence de la vie. París: Armand Colin.

Marin, C. (2014): La maladie, catastrophe intime. París: PUF.

Marin, C. (2019): Rupture(s). París: Editions de l'Observatoire.

Marin, C. y Zaccai-Reyners, N. (2013): Souffrance et douleur. Autour de Paul Ricœur. París: PUF. 